\title{
Knowledge and Attitude from Mothers on the Impact of Nutrition on the Growth of Under-Five Children in Buchi Compound, Kitwe District
}

\author{
Wilbroad Kondwani Chilenga ${ }^{1, *}$, Alfred Matafwali Sichilima ${ }^{2}$ \\ ${ }^{1}$ Department of Public Health, Michael Chilufya Sata School of Medicine, Copperbelt University, Ndola, Zambia \\ ${ }^{2}$ Department of Biological Sciences, School of Mathematics \& Natural Sciences, Copperbelt University, Kitwe, Zambia
}

Email address:

chilengawilbroad1@gmail.com (W. K. Chilenga)

${ }^{*}$ Corresponding author

To cite this article:

Wilbroad Kondwani Chilenga, Alfred Matafwali Sichilima. Knowledge and Attitude from Mothers on the Impact of Nutrition on the Growth of Under-Five Children in Buchi Compound, Kitwe District. Rehabilitation Science. Vol. 3, No. 3, 2018, pp. $43-53$.

doi: $10.11648 /$ j.rs.20180303.11

Received: October 26, 2018; Accepted: November 20, 2018; Published: March 1, 2019

\begin{abstract}
Malnutrition is defined by the World Health Organization as the cellular imbalance between supply of nutrients and energy and the body's demand for them to ensure growth, maintenance, and other specific functions. Malnutrition is one of the major causes of death in under-five children. There are many causes of malnutrition, one of them being inadequate maternal nutrition knowledge. This study was designed to assess the knowledge and attitude mothers with under-five children have on nutrition and how this impacts the growth of children. The study was carried out in Buchi compound of Kitwe district of Zambia. A cross sectional survey was done with 270 mothers as respondents. A structured questionnaire is to collect information on their knowledge and attitude towards nutrition and its impact on the growth of children below the age of five years. The data was analyzed using SPSS version 16. The results showed that the age composition of the study population had more persons below the age of 34 with a mean age of 27years. The majority of mothers were married and most of them were housewives. Many of the mothers had attained primary and secondary levels of education. Most of the mothers had good attitudes towards the importance of nutrition. Majority of mothers had some knowledge about nutrition, about $46 \%$ had an average nutritional knowledge score. Age, level of education, and occupation were significantly related to knowledge level at 0.05 level (P-values, 0.006, 0.000, 0.000 respectively). There was no significant relationship between marital status and knowledge level (P-value 0.112). The study concluded that mothers have some knowledge about nutrition and that education plays an important role in the acquisition of this knowledge. In addition to nutritional knowledge, the other observed important contributor to poor growth/nutritional status in children is poor social economic status. Generally, the nutritional status of the children was fairly normal though only the dietary aspect was assessed.
\end{abstract}

Keywords: Knowledge, Attitude, Nutrition, Growth, Buchi Township, Kitwe

\section{Introduction}

\subsection{Background Information}

Malnutrition is defined as a dietary condition that results from the deficiency or excess of one or more essential nutrients in the diet. Malnutrition is characterized by a variety of health problems, including the following; stunted growth, extreme weight loss, impairment of intellect and weakened resistance to infection. Severe cases of malnutrition can lead to death.

Children quickly suffer the effects of starvation than adults. According to the United Nations Children's Fund (UNICEF), malnutrition contributes to the mortality of more than six million children below the age of five each year. Typically, when children undergo starvation, they develop a condition called protein-energy malnutrition (PEM). The commonest forms of PEM are marasmus and kwashiorkor which are life-threatening conditions and occur in all developing countries. Marasmus occurs when a child is 
weaned earlier than normal and receives foods low in nutrients. Poor hygiene can also lead to repeated infections such as gastroenteritis in these children. A child with marasmus is very underweight, with no body fat and wasted muscles. Kwashiorkor on the hand occurs when a child is weaned later than normal and receives foods high in starch but low in proteins. This disease is characterized by water retention which tends to mask the child's abnormally low body weight and makes the face moon-shaped and the belly swollen.

There is usually an association of deficiency diseases with lack of vitamins or minerals. The effects of a vitamin or mineral deficiency on the body depend on the function of the particular nutrient lacking. For example, vitamin $\mathrm{A}$ is important for good vision, and severe deficiency of this vitamin may cause blindness. Because some vitamins and minerals have many functions, prolonged nutritional deficiencies can therefore have wide-ranging effects on health.

Diets that lack a wide variety of foods may result in vitamin deficiency diseases. For example, in countries where people eat maize as the staple food and only few other foods, diets may lack niacin, a B vitamin. Such diets may cause pellagra, a deficiency disease characterized by dermatitis, diarrhea, and dementia [1].

Some people find it difficult to meet their nutritional requirements. Women due to their menstrual cycle for example have a higher requirement for iron than men. Therefore, if their iron requirement is not met, they may develop anemia. Other nutritional deficiencies are influenced by geographic factors. There are some remote areas where the soil contains little iodine hence, the plants that grow there also contain little iodine and because few foods contain significant amounts of iodine, people living in these areas may suffer prolonged iodine deficiency, resulting in disorders of the thyroid gland. In developed countries the most common form of malnutrition is over nutrition, which can lead to obesity which in turn increases the risk of many diseases, including diabetes, heart disease, and arthritis. However, inadequate consumption of calories and protein is also common in the elderly and in people with certain diseases, such as anorexia nervosa.

'We guilty of many errors and many faults, but our worst crime is abandoning the children, neglecting the foundation of life. Many of the things we need, can wait but the child cannot. Right now is the time his bones are being made and his senses are being developed. To him we cannot answer tomorrow. His name is today'. Gabriela Mistral.

A child's development is influenced by a variety of factors. These are broadly categorized as follows; heredity guides a child's physical, cognitive, social, emotional, and personality aspect of development. Family members, peer groups, the school environment, and the community influence how children think, socialize, and become self-aware. Biological factors such as nutrition, medical care, and environment hazards in the air and water affect the growth of the body and mind. Economic and political institutions, the media, and cultural values all guide how children live their lives [2]. All these factors if not balanced have a negative effect on the health status of a child which in turn affects his or her development physically, mentally, and emotionally. It is the physical aspect of development on which this study will be focused, only on how nutrition affects the physical growth of a child.

In contrast to healthy eating which has many advantages and benefits, a diet which is very poor can cause several physical problems in children. A diet that has a high fat and calorie content can result in or lead to obesity, which highly interferes with physical fitness. In addition, it also raises the risk of cardiovascular diseases diabetes, and cancer. A diet lacking in proper nutrition can also result in stunted growth and bone disorders [3]. A study which was published in the "New England Journal of Medicine" by doctors H. Peter Chase and Harold P. Martin [4] measured children who were hospitalized for undernourishment during their first years of life. The Doctors found that these children who were hospitalized for undernutrition were consistently smaller than children who had not experienced undernutrition before, even three and four years later. At the other end of the spectrum, the academy of nutrition and diabetics suggests that poor nutrition in the form of overfeeding can contribute to weight issues later in a child's life.

Furthermore, studies have shown that if a woman is not adequately nourished during pregnancy or if her child is malnourished during the first two years of life, the child's physical and mental growth and development will be slowed [5]. This dawdling in child growth cannot be corrected when the child is older, hence it will affect the child for the rest of his or her life. The nutrition a child receives during the first few years of life can affect his/her health for years to come. Balanced nutrition is important to child development because children need specific nutrients to thrive and grow. Poor nutrition can result from lack of food as well as overeating, since nutrition is about more than simple caloric intake [6]. Proper child development relies on solid nutritional foundation, which includes the correct amount of each nutrient.

\subsection{Statement of Problem}

Studies have shown that poor physical growth in childhood can be a result of poor nutrition, which either can be because of undernourishment or over nourishment (the former being the most common cause of undesirable child development). Poor nutrition is a global problem, but it's more pronounced in the developing countries like Zambia, particularly the rural areas where access to health services is limited and information about healthy living is not effectively communicated or disseminated. While physical development generally proceeds in a very predictable manner, there are things that can have major influence on how and when kids achieve these physical milestones. Nutrition is one important factor that can impact a child's physical growth [7].

Even though significant progress has been made in 
ensuring that children are properly nourished, there are still main challenges that remain throughout the world. For Eastern and Southern Africa, stunting also known as chronic malnutrition, is of utmost concern. Additionally, 18 percent of under-fives are underweight (they weigh too little for their age); and 7 percent are suffering from acute malnutrition (also called wasting, a rapid loss of weight because of illness or insufficient food intake) (estimates by UNICEF). In comparison to underweight and wasting, stunting is largely irreversible, and it is affecting more children than the first two conditions combined in the region.

\subsection{Key Terms}

Anthropometry: The study and technique of taking body measurements, especially for use on a comparison or classification basis. It refers to the measurement of the human individual for the purposes of understanding human physical variation.

Child Development: Physical, intellectual, social, and emotional changes that occur from birth to adolescence

Household: Refers to one person who lives alone or a group of persons, related or unrelated who share food or make common provisions for food and other essentials for living.

Macronutrient: Nutrient required in large amounts for normal growth e.g. proteins

Knowledge: Refers to verbalized or demonstrated ability to reproduce from memory facts and principles.

Micronutrient: Nutrient only required in small amounts but essential for growth e.g. vitamins

Malnutrition: A lack of healthy foods in diet, or an excessive intake of unhealthy foods, leading to physical harm

Nutrient: A substance that provides nourishment to the body

Nutrition: the science that deals with foods and their effects on health

Nutrition knowledge: is defined as the understanding of different types of food and how food nourishes the body and influences health.

Nutrition Status: Refers to whether or not the child is underweight, stunted or wasted.

Stunting: it is defined as small height for age according to WHO

Undernutrition: To fail to provide someone with sufficient nutrients for proper development

Underweight: Refers to having low weight for age mainly due to chronic under nutrition or acute malnutrition

Wasting: Refers to having low weight for height according to WHO standard with a $<-2 \mathrm{SD}$ mainly due to acute malnutrition

\subsection{Theoretical Framework}

The theoretical approach has its origins in Becker's Microeconomic models of household production [8]. Becker [8] has proven in illuminating the household determinants of nutrition that a child's nutritional status (measured in terms of height for age or weight for age) relates to a set of health inputs. These inputs include the child's nutrient intake, whether the child is breastfed and for how long they are breastfed, preventive and curative medical care, and the quality and amount of time the caregivers spend doing carerelated activities with the child. The quality of the care time allocated to the child is likely influenced by the caregiver's age, experience, education, own health status and environmental factors. Nutrition status of the child is also affected by the mother's employment status, because the mother's employment translates into higher consumption of market-purchased inputs such as food and medical care which in turn improves the nutrition status of the child, but reduction in quality or quantity of parental care time reduces the nutritional status.

A child's nutritional status reflects the combined effects of many factors, including nutrient intake, health, birth order, and behavioural factors governed by parental preferences. A child's nutritional status indirectly provides an indicator of the child's overall health and also directly measures access to adequate nutritious foods. Malnutrition is a vigorous indicator of the presence of severe child deprivation. But the unfinished reality is that even today many children in the developing societies are deprived in health and nutrition. Malnutrition has been observed frequently as part of a vicious cycle that includes poverty and disease. These three factors (malnutrition, poverty, and disease) are interlinked in such a way that each contributes to the presence and presentation of the others. Anthropometry is widely recognized as one of the useful techniques to assess the growth and nutritional status of an individual or population [9].

Nutrient intake is recognized as one of the many environmental factors which act upon the genetic potential of the young child to influence his physical development or growth [10]. Sims et al further goes on to say that, malnutrition is a syndrome that occurs not in isolation, but within the context of an entire constellation of environmental factors which together contribute to the final manifestation of the problem. There is a belief that the nutritional status of underfive children must be assessed in relation to factors which characterize his/her near environment, particularly his/her family. The family functions as the near environment in the theoretical model which was developed to study the nutritional status for the developing child, and as such it plays a major role in providing an interchange between the child and the components of the more distal environment. In this model nutrient intake is viewed as an output of the family system resulting from the interaction of matter-energy and information flows within the system. The child is further described as being an independent ecosystem who processes nutrient supply in such a way as to produce his physical development and nutritional status as outputs of the system [10].

\section{Methodology}

This study is a descriptive cross - sectional study and the 
study involved the use of a structured questionnaire to collect data from randomly selected mothers with children below the age of five in Buchi compound. All the mothers interviewed gave informed consent and ethical standards were obeyed in this study. The research proposal for this study was approved by the Tropical Disease Research Centre's Ethics Review committee of Ndola Teaching Hospital. There was a total number of 270 mothers who responded to the questionnaire. After collection of data, all questions were coded, and manually entered into the Statistical Package for Social Sciences (SPSS) version 16.0 where all the statistical analysis were performed. The analysis done included descriptive statistics to determine frequencies of key parameters. And for variables of interest, the Pearson correlation test of association was computed to determine the relationship.

\section{Results and Data Analysis}

This chapter presents results of the study conducted in Buchi compound of Kitwe district. The results are organised as per the objectives of the study. The objectives of the study were as follows: to determine the knowledge and attitude of parents on nutrition and growth of children, to assess the role of parental care on the growth of children, to assess the nutritional status of under five children using only the dietary diversity.

\subsection{Demographic Characteristics of Participants}

A total of 270 mothers were interviewed, and all these had ages ranging from 18 to 52 years, the mean age was 27.

\section{Age Distribution}

The ages ranged from 18 to 52 years, with a mean age of 27 , median 26 , mode of 24 and standard deviation of 6.316. the table below shows the frequency of age distribution:
Table 1. Frequency of age distribution.

\begin{tabular}{llll}
\hline & & Frequency & Percent \\
\hline & 15 to 24 & 102 & 37.8 \\
& 25 to 34 & 132 & 48.9 \\
Grouped age distribution & 35 to 44 & 32 & 11.9 \\
& Above 45 & 4 & 1.5 \\
& Total & 270 & 100.0 \\
\hline
\end{tabular}

Marital Status

68.5 percent of the respondents were married, 24.4 percent were single, 4.1 were divorced and 3.0 percent belonged to other statuses (widow, widower, separated).

Table 2. Marital status frequency distribution.

\begin{tabular}{llll}
\hline & & Frequency & Percent (\%) \\
\hline & Single & 66 & 24.4 \\
& Married & 185 & 68.5 \\
Marital Status & Divorced & 11 & 4.1 \\
& Other & 8 & 3.0 \\
& Total & 270 & 100.0 \\
\hline
\end{tabular}

Level of Education

About 160 of the mothers interviewed (approximately $59.3 \%$ ) had attained a secondary level of education, $33.3 \%$ were in primary school or stopped school at primary school level, $4.4 \%$ were in college, only about $3 \%$ of the respondents had no formal education.

Table 3. Level of education frequency distribution.

\begin{tabular}{llll}
\hline & & Frequency & Percent (\%) \\
\hline \multirow{3}{*}{ Level of } & No formal education & 8 & 3.0 \\
education & Primary & 90 & 33.3 \\
& Secondary & 160 & 59.3 \\
& Tertiary & 12 & 4.4 \\
& Total & 270 & 100.0 \\
\hline
\end{tabular}

Occupation

Of the 270 women interviewed, only 8 were employed, 114 were self-employed, and 153 were unemployed, as shown in the figure below:

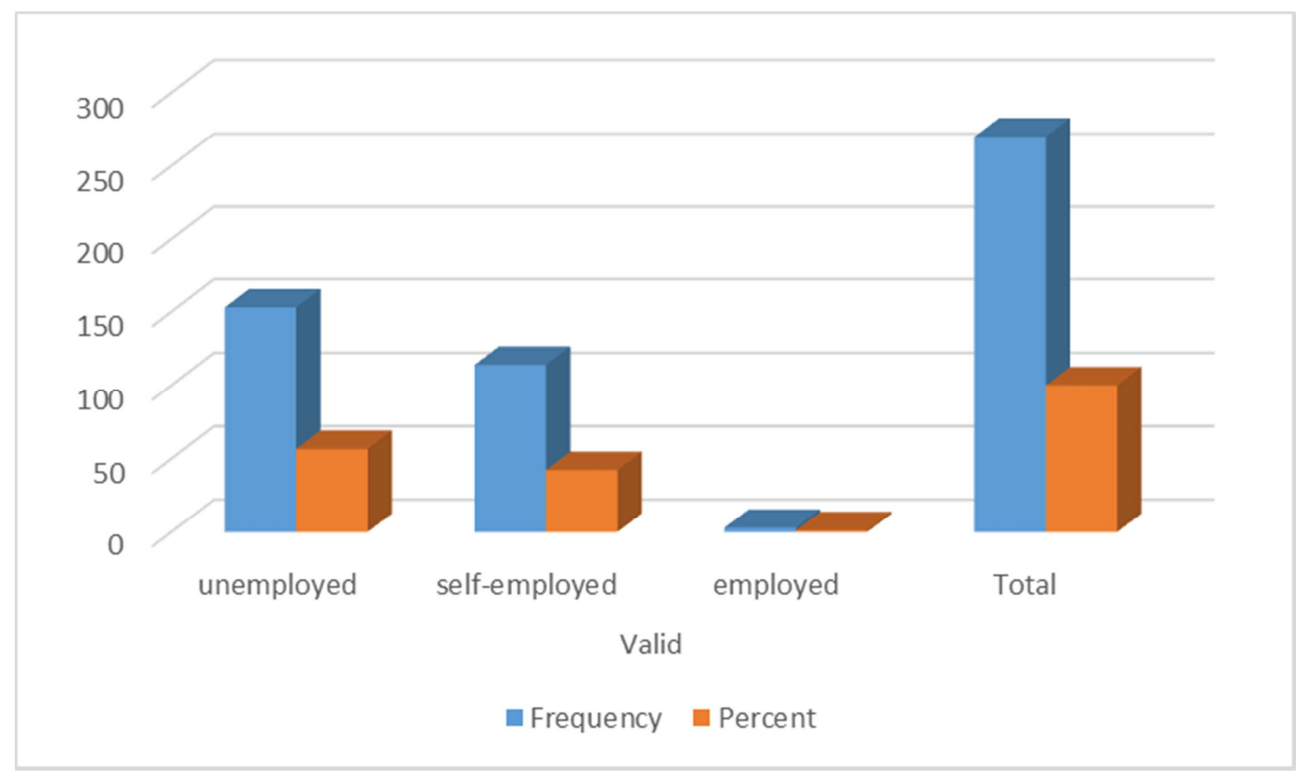

Figure 1. Frequency distribution of occupation. 


\subsection{Importance of Nutrition}

224 of the participants, that is 83.0 percent thought nutrition is important for child growth and 46 (17.0\%) thought it was not important.

Table 4. Importance of Nutrition

\begin{tabular}{llll}
\hline & & Frequency & Percent (\%) \\
\hline \multirow{4}{*}{ Role of nutrition in growth } & Yes & 224 & 83.0 \\
& No & 46 & 17.0 \\
& Total & 270 & 100.0 \\
\hline
\end{tabular}

\subsection{Cross - Tabulation of Some Variables}

Grouped Age and Knowledge about Proteins

This figure shows the association between the number of women who know what proteins are with their age. Of the 73 women that were between the ages of 15 to 24 , only 29 knew what proteins are, 61 of the 71 women between 25 to 34 years of age knew what proteins, of the 32 women between 35 and 44 years, about 21 knew what proteins are, and of the 4 women above $45 y e a r s$, only 1 didn't know what proteins are.

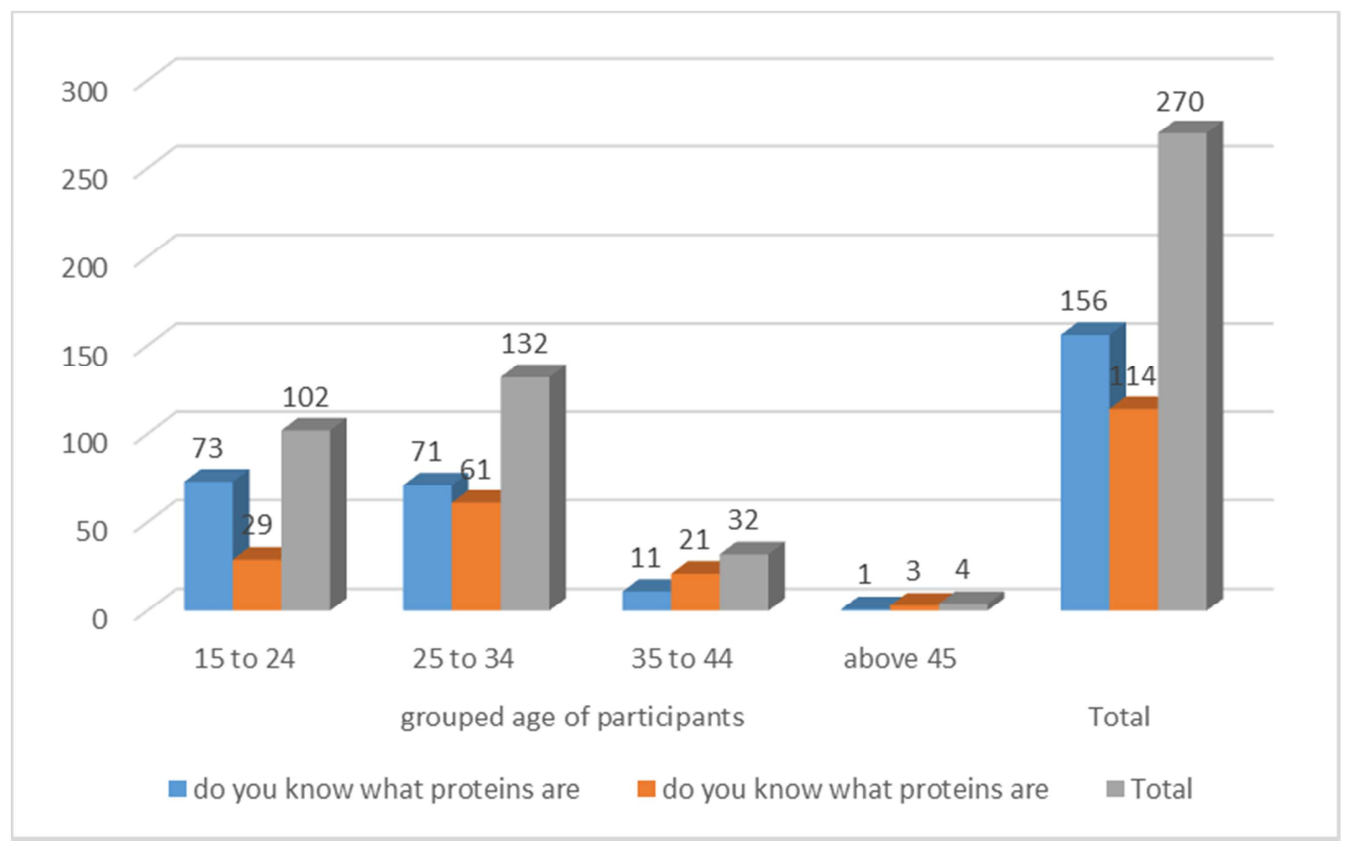

Figure 2. Showing association between age and the number of women who know what proteins are.

Grouped Age and Knowledge about Fats

There were 102 women who were between the ages of 15 to 24 years, and of that 31 did not know what fats are. Of the 132 women who were between ages 25 to 34 years, 70 knew what fats are. Those between 35 to 44 years old, 20 out of the total of 32 did not know what fats are. And of the 4 women who were above 45 years of age, 3 did not know what fats are.

Table 5. Shows the association between the number of women who know what fats are with their age.

\begin{tabular}{|c|c|c|c|c|}
\hline & \multicolumn{3}{|c|}{ Do you know what fats are } & \multirow{2}{*}{ Total } \\
\hline & & Yes & No & \\
\hline \multirow{5}{*}{ Grouped age of participants } & 15 to 24 & 71 & 31 & 102 \\
\hline & 25 to 34 & 70 & 62 & 132 \\
\hline & 35 to 44 & 12 & 20 & 32 \\
\hline & Above 45 & 1 & 3 & 4 \\
\hline & Total & 154 & 116 & 270 \\
\hline
\end{tabular}

Grouped Age and Knowledge about Nutrients found in Various Foods

There were 228 women who did not know the nutrients found in the various foods their children eat, only 42 women knew, and of these 42, 21 belonged to the age group of 15 to 24, 18 were between the ages 25 and 34, and the remaining 3 belonged to those between 35 and 44 years of age as shown in the table below;

Table 6. Shows association between the number of women who know the nutrients found various foods with their age.

\begin{tabular}{|c|c|c|c|c|}
\hline & & \multicolumn{2}{|c|}{ Do you know the nutrients found in various foods you eat } & \multirow{2}{*}{ Total } \\
\hline & & Yes & No & \\
\hline \multirow{2}{*}{ Grouped age of participants } & 15 to 24 & 21 & 81 & 102 \\
\hline & 25 to 34 & 18 & 114 & 132 \\
\hline
\end{tabular}




\begin{tabular}{lllll}
\hline & \multicolumn{2}{l}{ Do you know the nutrients found in various foods you eat } \\
\cline { 2 - 3 } & Yes & No & \\
\cline { 2 - 4 } & 35 to 44 & 3 & 29 & 32 \\
Above 45 & 0 & 4 & 4 \\
Total & 42 & 228 & 270 \\
\hline
\end{tabular}

Grouped Age and Guide for Balanced Diet

From the 270 mothers interviewed, 33 of the 102 women in the ages of 15 to 24 have a guide, 38 out of the 132 who belong to age group of 25 to 34 have a guide, and 3 of the 32 women with ages ranging from 35 to 44 have a guide as shown in the bar figure below;

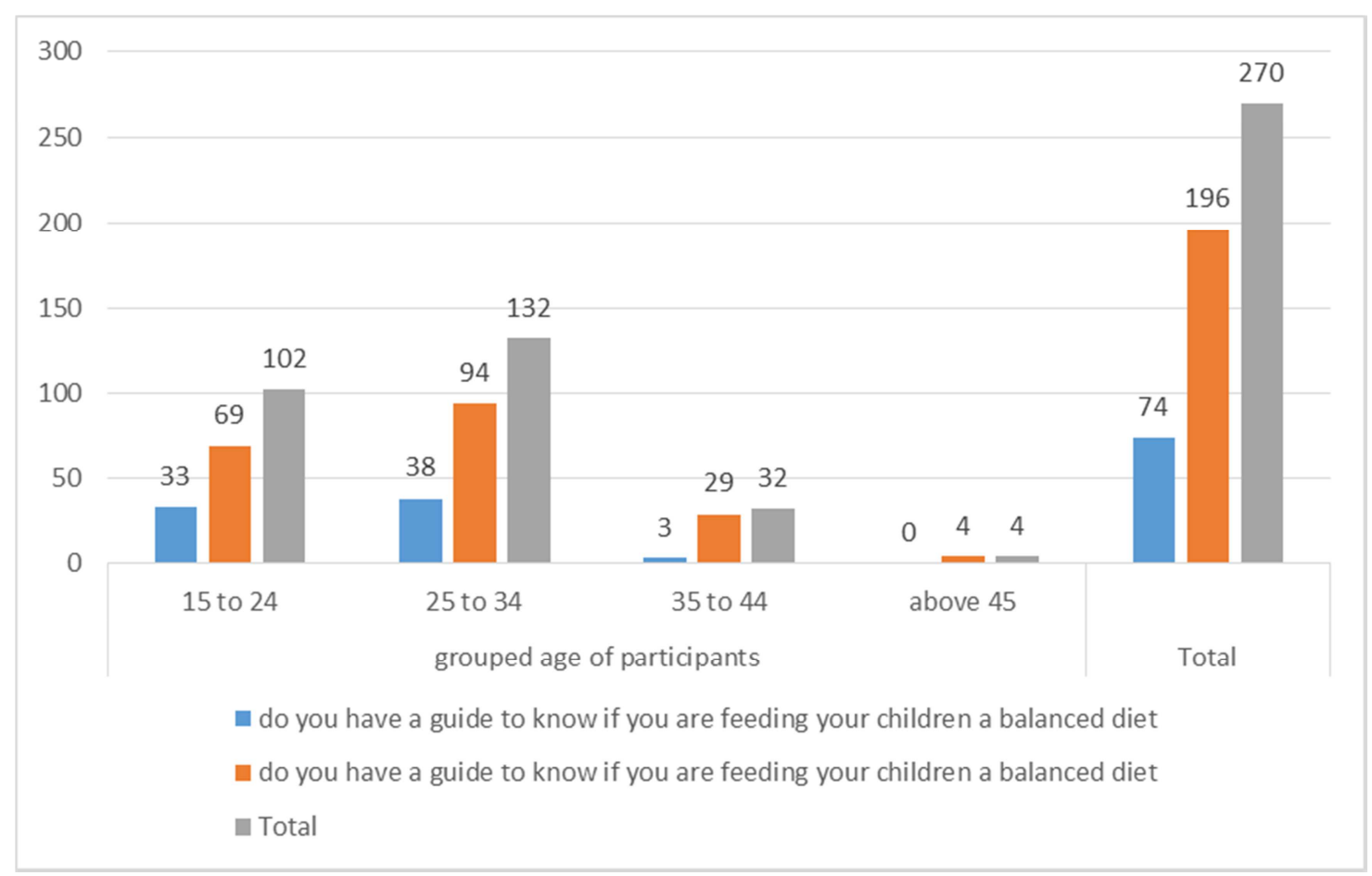

Figure 3. Association between age of participants and whether or not they have a guide for balancing the diet.

Level of Education and Knowledge about Proteins

There were 156 women who knew what proteins are, 114 did not know what proteins are. 12 of the women who knew what proteins are, were in tertiary school or had attained tertiary education, 111 had attained a secondary level education, those who had only attained a primary level education were 31 , and the remaining 2 had no formal education.

Table 7. Shows the association between level of education of participants and whether or not they know what proteins are.

\begin{tabular}{lllll}
\hline & & \multicolumn{2}{l}{$\begin{array}{l}\text { Do you know what } \\
\text { proteins are }\end{array}$} & \multirow{2}{*}{ Total } \\
\cline { 3 - 4 } & & Yes & No & \\
\hline \multirow{3}{*}{ Level of } & No formal education & 2 & 6 & 8 \\
education & Primary & 31 & 59 & 90 \\
& Secondary & 111 & 49 & 160 \\
& Tertiary & 12 & 0 & 12 \\
& Total & 156 & 114 & 270 \\
\hline
\end{tabular}

Level of Education and Knowledge about Fats.

Of the 154 women who knew what fats are, 12 had attained a tertiary level education, 111 had a secondary level education, 30 had a primary level education, and only 1 had no formal education.

Table 8. Association between level of education and whether or participants knew what fats are.

\begin{tabular}{|c|c|c|c|c|}
\hline & & \multicolumn{2}{|c|}{ Do you know what fats are } & \multirow{2}{*}{ Total } \\
\hline & & yes & No & \\
\hline \multirow{5}{*}{$\begin{array}{l}\text { Level of } \\
\text { Education }\end{array}$} & No formal education & 1 & 7 & 8 \\
\hline & Primary & 30 & 60 & 90 \\
\hline & Secondary & 111 & 49 & 160 \\
\hline & Tertiary & 12 & 0 & 12 \\
\hline & Total & 154 & 116 & 270 \\
\hline
\end{tabular}

Level of Education and Knowledge on Nutrients found in Various Foods

Of the 42 women who had some knowledge on the nutrients found in the various foods, 2 had no formal education, 5 had a primary level education, 25 had a secondary level education, and 10 had a tertiary level education. As shown in the table below; 
Table 9. Association between level of education of the participants and whether or not they know what nutrients are found in various foods.

\begin{tabular}{lllll}
\hline & & \multicolumn{2}{l}{ Do you know the nutrients found in various foods you eat } & \multirow{2}{*}{ Total } \\
\cline { 2 - 4 } & Yes & 2 & 6 & 8 \\
& No Formal Education & 5 & 85 & 90 \\
Level of Education & Primary & 25 & 135 & 160 \\
& Secondary & 10 & 2 & 12 \\
Total & Tertiary & 42 & 228 & 270 \\
\hline
\end{tabular}

Level of Education and Guide for a Balanced Diet

Out of the 270 participants, 196 did not follow any guide for a balanced diet for their children, the remaining had some sort of a guide. From the ones who had a guide (which was about 74), about 9 had attained tertiary education, 48 had a secondary school level education, 16 stopped in primary school and out of the 8 who had no formal education, only 1 followed a balanced diet guide as shown in the bar figure below;

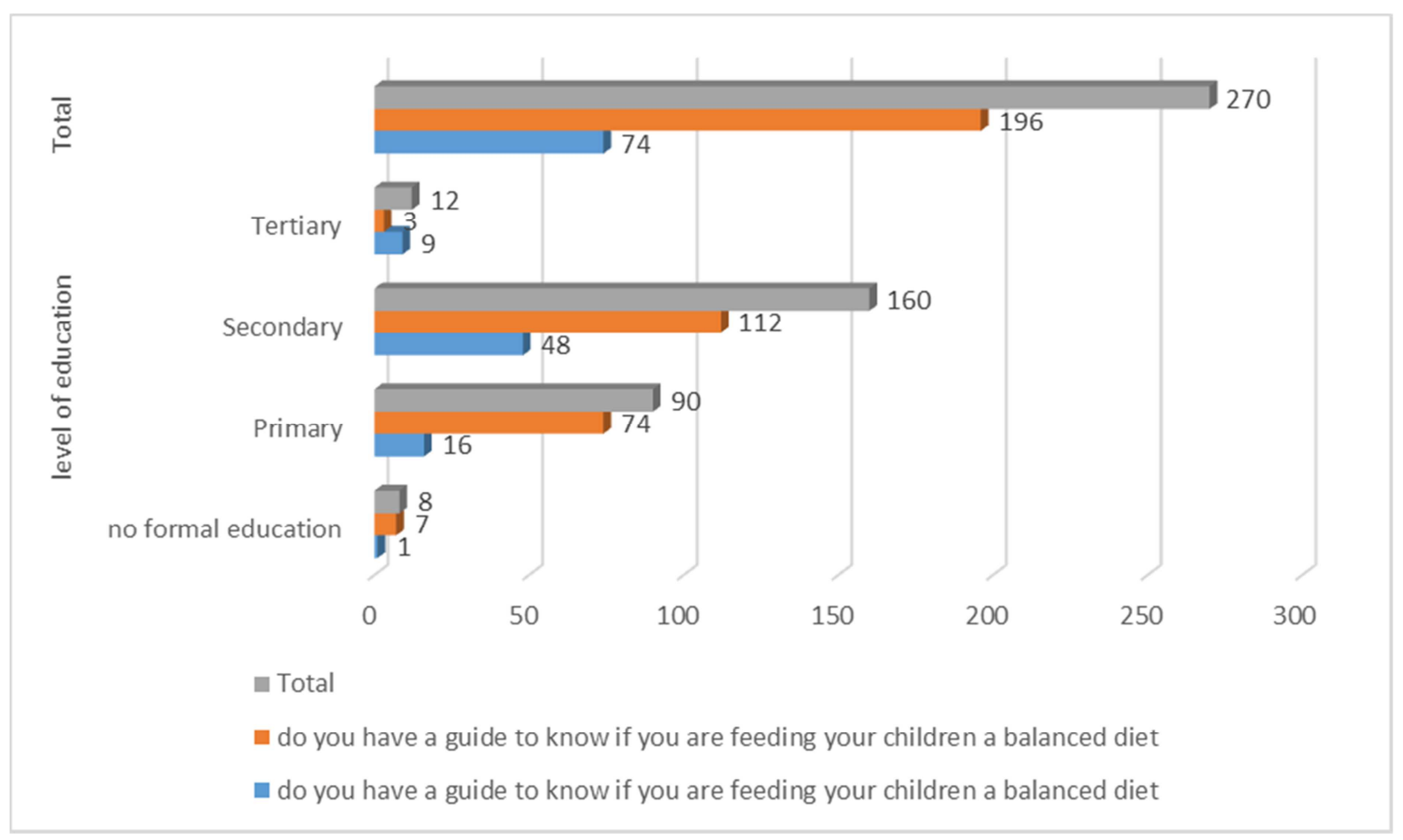

Figure 4. Association between level of education of participants and whether or they use a balanced diet guide.

\subsection{Attitude Score}

Most of the mothers had good attitudes towards nutrition and its importance in children. About $77.4 \%$ of mothers had good attitude, $14.1 \%$ had fair attitude and $8.1 \& \%$ had poor attitude as shown in the figure below;

Table 10. Attitude score.

\begin{tabular}{lll}
\hline Attitude Score & Frequency & Percent $(\%)$ \\
\hline Poor & 23 & 8.5 \\
Fair & 38 & 14.1 \\
Good & 209 & 77.4 \\
Total & 270 & 100.0 \\
\hline
\end{tabular}

\section{Key}

Score: Grade

0: Poor

1: Fair

2: Good

\subsection{Knowledge Score}

Only about $8.1 \%$ (22) of the mothers had a high knowledge score, 125 (46.3\%) had average knowledge and 123 women had little to no knowledge about nutrition as shown in the table below;

Table 11. Knowledge score.

\begin{tabular}{lll}
\hline Knowledge score classification & Frequency & Percent (\%) \\
\hline Low & 123 & 45.6 \\
Average & 125 & 46.3 \\
High & 22 & 8.1 \\
Total & 270 & 100.0 \\
\hline
\end{tabular}

Key for Knowledge score

Score: Grade

$0-2$ : Low

$3-4$ : Average

5-6: High 
Knowledge Score and Level of Education

Table 12. Shows the association between nutritional knowledge of mothers and level of education.

\begin{tabular}{|c|c|c|c|c|c|}
\hline & & \multicolumn{3}{|c|}{ Knowledge Score } & \multirow{2}{*}{ Total } \\
\hline & & 1 to 2 & 3 to 4 & 5 to 6 & \\
\hline \multirow{5}{*}{$\begin{array}{l}\text { level of } \\
\text { education }\end{array}$} & no formal education & 7 & 1 & 0 & 8 \\
\hline & Primary & 64 & 25 & 1 & 90 \\
\hline & Secondary & 52 & 95 & 13 & 160 \\
\hline & Tertiary & 0 & 4 & 8 & 12 \\
\hline & Total & 123 & 125 & 22 & 270 \\
\hline
\end{tabular}

\subsection{Nutritional Assessment of Children Using Dietary Diversity Only}

There were five variables assessed, namely vegetables, fruits, milk \& dairy products, meat \& meat alternatives, and sweets \& fats. Mothers were asked the various types of food they gave their children in the previous week. For example, under vegetables there were about eight types of vegetables and the mothers chose which ones they had eaten the previous week and they were scored accordingly. 73 of the mothers interviewed had infants less than six months so this part of the questionnaire did not apply to them. The results are shown in the table below;

Table 13. Frequency distribution of dietary diversity.

\begin{tabular}{|c|c|c|c|c|c|}
\hline \multirow{2}{*}{ Dietary diversity variables } & \multicolumn{4}{|l|}{ Score } & \multirow{2}{*}{ Total } \\
\hline & Poor & Fair & Good & Not applicable & \\
\hline Vegetables & $7(2.6 \%)$ & $149(55.2 \%)$ & $41(15.2 \%)$ & $73(27.0 \%)$ & $270(100 \%)$ \\
\hline Fruits & $82(30.4 \%)$ & $112(41.5 \%)$ & $3(1.1 \%)$ & $73(27.0 \%)$ & $270(100 \%)$ \\
\hline Milk \& Dairy Products & $186(68.9 \%)$ & $11(4.1 \%)$ & 0 & $73(27.0 \%)$ & $270(100 \%)$ \\
\hline Meat \& Meat Alternatives & $73(27.0 \%)$ & $91(33.7 \%)$ & $33(12.3 \%)$ & $73(27.0 \%)$ & $270(100 \%)$ \\
\hline Sweets \& Fats & $125(46.3 \%)$ & $71(26.3 \%)$ & $1(0.4 \%)$ & $73(27.0 \%)$ & $270(100 \%)$ \\
\hline
\end{tabular}

\subsection{Relationship Between Socio-Demographic Factors and Some Variables (P-Values)}

The main independent variables considered here were questions pertaining to nutritional knowledge and level of knowledge and dietary diversity being the dependent variables. All values less than or equal to 0.05 show a statistical significance.

Table 14. Association between Socio-demographic factors and knowledge variables (P-values).

\begin{tabular}{|c|c|c|c|}
\hline \multirow[b]{2}{*}{ Demographic factors } & \multicolumn{3}{|l|}{ Independent variables } \\
\hline & $\begin{array}{l}\text { Do you think good nutrition is important } \\
\text { for child growth }\end{array}$ & $\begin{array}{l}\text { Do you Know what proteins are and in what foods } \\
\text { they are found }\end{array}$ & $\begin{array}{l}\text { Do you know what } \\
\text { fats are }\end{array}$ \\
\hline Grouped Age & 0.150 & 0.000 & 0.003 \\
\hline Marital Status & 0.323 & 0.026 & 0.126 \\
\hline Level of Education & 0.001 & 0.000 & 0.000 \\
\hline Occupation & 0.082 & 0.003 & 0.005 \\
\hline
\end{tabular}

Table 14. Continued.

\begin{tabular}{llll}
\hline \multirow{2}{*}{ Demographic factors } & Independent variables & \\
\cline { 2 - 4 } & $\begin{array}{l}\text { Do you know the nutrients found in various foods } \\
\text { you give your children }\end{array}$ & $\begin{array}{l}\text { Do you know the } \\
\text { sources for vitamin A }\end{array}$ & $\begin{array}{l}\text { Do you have a guide for balancing } \\
\text { the diet of your children }\end{array}$ \\
\hline Grouped Age & 0.261 & 0.789 & 0.044 \\
Marital Status & 0.284 & 0.927 & 0.811 \\
Level of Education & 0.000 & 0.876 & 0.000 \\
Occupation & 0.000 & 0.681 & 0.04 \\
\hline
\end{tabular}

\section{Discussion, Recommendations, and Conclusion}

\subsection{Socio-Demographic Characteristics}

The demographic and socioeconomic characteristics identified in the study population were; Age composition, Marital status, Education, and Occupation of the mothers. The study showed that there were more married women than those who were single, divorced, or widowed, this shows that the moral values of family are still being upheld, and also it provides or creates a conducive environment for bringing up children. It was found that majority of the mothers interviewed were married, this is good because if both parents are working then the household income will increase. Previous studies indicate that the greater the household income, the higher the ability of the family to purchase adequate quantities of nutritious foods [11]. A study that was carried out in Kwale, Kenya showed that demographic and social-economic factors were the underlying causes of poor nutritional status of children [12].

The study showed that most women had not gone past secondary education hence contributing to the high levels of unemployment. Only a few women had either completed tertiary education or were still attaining tertiary education. Previous studies have observed that education plays a key role in determining the lifestyle and status that an individual enjoys in a society [13]. Studies have also shown that a mother's education is closely linked to the nutritional status of children. A study that was done by [12] showed the 
importance of maternal education for child health and nutrition. It was observed in this study that children with mothers who had some secondary or tertiary education had a good dietary diversity, even though many did not manage this, the main reason for failure to provide a balanced diet for their children being lack of resources. A study conducted by [11] identified that greater education for mothers contributes to new skills, beliefs and choices about sound health and nutritional practices. Similarly, a study done by [14] in the Democratic Republic of Congo established that the education of mothers has a positive effect on child health. This failure of attainment of appropriate education levels that was observed in the participants needs to be addressed if we have any hope of improving the nutritional status of children. Furthermore, an educated woman will have a positive impact on her family and also contribute to national development.

The study showed that only a few women were employed, this is mostly due to lack of attainment of appropriate levels of education seen in the community, though almost about half of the women had small scale business they were managing hence contributing a little to the day to day needs of the family. This only shows that there is need for women empowerment in order for them to be able to contribute to the family income and ease straining in the household basic needs.

As [15] illustrated, a livelihood comprises the capabilities of the family, the assets they have (this includes both material and social resources) and activities required for a means of living. It was observed in this study that the main source of livelihood for the families in Buchi compound is selfemployment. Either the father or mother or both depend on a small scale business for income, only a few had some form of formal employment. And everything they earn is distributed among the various basic needs of the family. More importantly it was observed that the monthly income of families was not sufficient enough to enable them afford a diet which is diverse, or provide proper housing, or to give their children good education and access to quality healthcare, which is the case in most rural areas.

\subsection{Maternal Nutritional Knowledge and Attitude}

Nutrition knowledge is defined as the understanding of different types of food and how the food we eat nourishes the body and influences health cited by [16]. Food choices and preparation is affected by nutritional knowledge. Increased knowledge in women is a powerful weapon against malnutrition, because this increased knowledge coupled with skills enable women earn higher incomes and by doing so enhancing the food security of the family and also improving the quality of care given to the family, herself inclusive. The other important benefit is that knowledge empowers mothers to make optimal choices for nutritious and safe food [17].

In this study majority of the mothers interviewed had average to low knowledge on nutrition, with almost half of them scoring low on the knowledge score. Only a small percentage of them had a high nutritional knowledge score. It was observed that there is a positive correlation between level of education and nutritional knowledge, with those mothers who had reached secondary and tertiary education having a higher score than those who had no formal education or had ended at primary level. This is similar to what was found in another study, where it was shown that mother's nutritional knowledge increases parallel with education level [18].

The study findings showed that majority of mothers were not aware of any vitamin A and protein source. The most mentioned sources were fruits and beans respectively, most did not know what nutrients are found in the various food given to children. A study which was done in Bangladesh showed that the children's nutritional habits are positively influenced or affected by higher nutritional knowledge of mothers [19].

Research has shown that a mother is the principal provider of primary care needed by her children in the first six years of their lives. And the type of care she provides largely depends on the knowledge and understanding that she has on basic nutrition and health care. Therefore, it is reasonable to surmise that her educational status influences her child-care practices [20]. Studies have shown that mothers with high nutritional knowledge acquired primarily outside school are able to utilize food more effectively by choosing a more diversified diet for their children's nutrition [21]. This shows that nutritional knowledge is not only acquired at school, hence mothers who missed that chance to go to school can still acquire nutritional knowledge in other ways, e.g. from neighbours or friends in the community where they live or more importantly at clinics when they take their children for under-five clinic visits. The other important factor influencing nutritional status of children is the economic status of the family, in this study for example it was observed that despite some mothers having an average to high nutritional score, the food they gave their children was determined by what they can afford and not necessarily on what food is of nutritional benefit to the children. This is similar to what was found by [22], were it was observed that nutritional knowledge alone is not adequate to ensure children's nutritional security, and hence, for nutrition education programmes to have a positive impact, facilitational strategies must be incorporated.

Most of the mothers interviewed had a good attitude on nutrition and how it affects the growth of children. It was observed that attitude is somewhat determined by the level of education, as most women who had good attitudes were those who had attained secondary or tertiary levels of education.

\subsection{Nutritional Status of the Children}

Most of the parents only give their children what is available on that particular day, not taking into consideration the nutrient requirement of the children. This is mostly due to lack of resources, as most of the mothers try to feed their children the right types of food but failure to afford causes them to manage with the little they have. In this study, only the dietary aspect was assessed, the physical indicators for assessing the nutritional status of children was not done. 
Mothers were interviewed on the various foods they give their children and the responses were scored accordingly. It was observed that many mothers are able to give their children a variety of vegetables and proteins when they have but this is not always the case. It was also observed that most of the children are taking inadequate milk and milk derivatives as they scored poor on the dietary diversity score.

There are two main reasons observed as causing these poor scores in dietary diversity, the first one is failure to afford and the second is lack of knowledge on what foods contain which nutrients. This is similar to what was observed in another study, were it was found that the household income and maternal nutrition knowledge are positively correlated with the nutritional status of children [23]. Therefore, there is need for educating women on the foods which are important for child growth, especially during under-five clinic. There is also need to encourage young girls to finish their education, because by doing so, they will contribute positively to the family income and also they will be equipped with basic knowledge needed for raising children with good nutritional status.

\section{Conclusion}

Majority of mothers are married, though most of them are only housewives hence most of the families depend solely on the husband for all household needs. Most of the mothers have attained primary and secondary levels of education. Some mothers are self-employed though in most cases it's never enough for the household. The total household income is shared among basic needs with food and house rent taking the highest share as health care and savings take less. The study concluded that majority of mothers have some nutritional knowledge, though low or average in most cases. Most women fail to attain tertiary level of education or even to complete secondary level of education, which explains the low levels of knowledge observed in the study. Generally, most children had a normal nutritional status, though an effective assessment involving use of anthropometry measurements combined with dietary diversity assessment needs to be done.

\section{Recommendations}

In line with the results found in this study, the following are the recommendations that should be made in order to improve the nutritional status of children under the age of five, which will result in good growth.

There is need to encourage women on the importance of exclusive breastfeeding, this is because in order to achieve good nutritional status for children, there is need to start feeding them rightly from the time they are born.

The study showed the importance of nutritional knowledge, hence, there is need to educate women more on nutrition. As earlier started, when a woman is educated she is more likely to provide better health care in terms of good nutrition and also good hygiene, this in turn will improve the nutritional status of children.

A Survey like this needs to be conducted at intervals of at least five years, so as to help in assisting the government learn more about the nutritional status of the people they govern and come up with plans on how to improve conditions of those affected.

\section{Acknowledgements}

I would like to give special thanks to my supervisor Dr Sichilima, without whose efforts I wouldn't have made it this far with my proposal. I would also like to recognize the help and encouragements from friends, family, and especially my significant other who highly motivated me throughout this research.

\section{Source of Support}

Nil

\section{Conflict of Interest}

None

\section{Abbreviations}

AIDS: Acquired Immune Deficiency Syndrome

CBU: Copperbelt University

DHS: Department Human Services

HIV: Human Immunodeficiency Virus

IQ: Intelligent Quotient

MDGS: Millennium Development Goals

NCH: National Center Health Statics

TDRC: Tropical Diseases Research Centre

UNICEF: United Nation Children's Fund

WHO: World Health Organization

\section{References}

[1] Microsoft $®$ Encarta $(\circledR 2$ 2009. (C) 1993-2008 Microsoft Corporation. All rights reserved.

[2] Jones H. Munang'andu, (2013). Pediatric Practice and Child Development.

[3] Martinez B, Webb M. F, Gonzalez A, et al, 2018. Complementary Feeding Intervention on Stunted Guatemalan Children: A Randomised Controlled Trial. BMJ Paediatrics Open.

[4] H. P. Chase \& H. P. Martin (1970). Undernutrition and child development.

[5] UNICEF, WHO, UNESCO, UNFPA, UNDP, UNAIDS, WFP, (2010). Facts of Life (fourth edition).

[6] Dakota Karratti, (2015). How Poor Nutrition Affects Child Development.

[7] Kendra Cherry, (2015). Physical Development in Childhood.

[8] Becker S. Gary, 1965. A Theory of the Allocation of Time. The Economic Journal. 
[9] Rao S, Joshi S. B, \& Kelkar R. S, 2000. Changes in Nutritional Status and Morbidity over time among Pre-school Children from Slums in Pune, India. Indian Pediatr.

[10] Laura S. Sims, Beatrice Paolucci \& Portia M. Morris, 2010. A Theoretical Model for the Study of Nutritional Status: An Ecosystem Approach. Ecology of Food and Nutrition journal.

[11] Miller, J. E. \& Rodgers, Y. V., 2009. Mother's Education and Children's Nutritional Status: New Evidence from Cambodia. Asian Development Review. 26 (1): 131-165.

[12] Adeladza, T. A., 2009. The Influence of Socio-economic and Nutritional Characteristics on Child Growth in Kwale District of Kenya. African Agriculture Nutrition and Development. 9 (7):1584-5374.

[13] Kenya National Bureau of Statistics (KNBS) and ICF Macro. 2010. Kenya Demographic and Health Survey 2008-2009. Calverton, Maryland: KNBS and ICF Macro.

[14] Emina, J. B.-O., Kandala, N.-B., Inungu, J. \& Yazoume, Y., 2011. Maternal education and child nutritional status in the Democratic Republic of Congo. Public Health and Epidemiology. 3 (12): 576-592.

[15] Piya, L., Maharjan, K. L. \& Joshi, N. P., 2011. Livelihood Strategies of Indigenous Nationalities in Nepal:A Case of Chepangs. Journal of International Development and Coope ration. 77 (2): 100-101.

[16] Margaret B. Gichana, 2013. Nutritional Knowledge of Mothers and Nutritional Status of their Children 6-59 months under Malezi Bora Programme in Kawangware Sub Location, Dagoretti, Nairobi County.
[17] Ongosi, A. N., 2010. Nutrient Intake and Nutrition Knowledge of Lactating Women (0-6) months postpartum) in a Law Socio-Economic Area in Nairobi, Kenya, Pretoria: University of Pretoria.

[18] Variyam, J. N. et al., 1999. Mothers' Nutrition Knowledge and Children's Dietary Intakes. American Agricultural Economics Association. 81 (2): 373-384.

[19] Faraque A. S, Ahmed T, Islam M. M, Hossain M. I, Roy S. K, Alam N, Kabir I, \& Sack D. A, 2008. Nutrition Basis for Healthy Children and Mothers in Bangladesh. Health Population Nutrition. 26 (3): 325-339.

[20] Christian, P., Abbi, R., Gujral, S. \& Gopaldas, T., 1988. The role of maternal literacy and nutrition knowledge in determining children's nutritional status. Food and Nutrition Bulletin, 10 (4).

[21] Fransesco, B., 2010. Child Nutrition in Mozambique in 2003: The Role of Mother's Education and Nutrition Knowledge. Economic and Human Biology. 8 (3): 331-45.

[22] Waihenya, E., Kogi-Makau, W. \& Muita, J., 1996. Maternal nutritional knowledge and the nutritional status of preschool children in a Nairobi slum. East Africa Medical. 73 (7): 41923.

[23] Quadri J. Akorede \& Ojure M. Abiola, 2013. Assessment of Nutritional Status of Under Five Children in Akure South Local Government, Ondo State, Nigeria. Department of Nutrition and Dietetics, Federal University of Agriculture. 